\title{
IDENTITY AND DIASPORIC TRAUMA IN MIRA JACOB'S THE SLEEPWALKER'S GUIDE TO DANCING
}

\author{
Jameel Alghaberi ${ }^{1}$ and Sanjay Mukherjee ${ }^{2}$ \\ 1,2 Department of English and Comparative Literary Studies, \\ Saurashtra University, Rajkot, India
}

\begin{abstract}
This article explores the assimilation politics in Mira Jacob's novel The Sleepwalker's Guide to Dancing (2013). The intersection of memory, trauma, and mourning with reference to immigrant experience is discussed. In terms of assimilation, Barkan's six stage model is critiqued, and diasporic 'hybridity' is proposed as an alternative to the notion of total assimilation. In the analysis of traumatic experience, the paper makes reference to Caruth's formulations of the 'abreactive model'. The Sleepwalker's Guide to Dancing is a transcultural text that represents the gap that truly exists between the first-generation immigrants and their offspring. It is a typical trauma novel featuring timeless and unspeakable experiences. The novel does not present a postcolonial collective trauma but invariably an example of diasporic imagined trauma. By presenting two contrasting generations in her novel, Mira Jacob attempts to highlight the dilemmas that baffle diasporas in the United States particularly of those that resist assimilation. Much of the narrative projects the haunting presence of home, and the anguish of personal loss experienced by first generation immigrants. Moreover, the novel questions the nostalgic and romantic engagements with the past and it promotes a bold affirmation of the culture of the adopted land. In other words, Mira Jacob calls for more genuine engagements with the new culture that the second and the third-generation immigrants are more exposed to than their home culture because their in-between status leaves them with no choice.
\end{abstract}

Keywords: assimilation, memory, identity, trauma, diasporic experience

\section{Article history:}

Submitted: 15 February 2021

Reviewed: 05 April 2021

Revised: 18 April 2021

Accepted: 22 May 2021

Published: 1 June 2021

\author{
Contributor roles: \\ Conceptualization J.A. (lead); Textual analysis J.A. (lead); \\ Supervision, Validation, Methodological Appropriation S.M. (lead); \\ Formal Analysis; Critical Evaluation J.A., S.M. (equal); \\ Writing - original draft J.A. (lead); \\ Writing-review and editing, S.M. (lead).
}

Copyright (C) 2021 Jameel Alghaberi and Sanjay Mukherjee

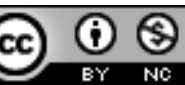

This open access article is published and distributed under a CC BY-NC 4.0 International License which permits non-commercial use, distribution, and reproduction in any medium, provided the original author and source are credited. Permissions beyond the scope of this license may be available at abujamaljameel@gmail.com. If you want to use the work commercially, you must first get the authors' permission.

Citation: Alghaberi, J., \& Mukherjee, S. (2021). Identity and Diasporic Trauma in Mira Jacob's “The Sleepwalker's Guide to Dancing". English Studies at NBU, 7(1), 51-68.

https://doi.org/10.33919/esnbu.21.1.4

Jameel Alghaberi is a PhD scholar in the English Department at Saurashtra University, Rajkot India. His research interests include diaspora studies, postcolonial interactions, cultural identity, and hybridity. E-mail: abujamaljameel@gmail.com

https://orcid.org/0000-0003-1863-9403

Prof. Sanjay Mukherjee is the Head of the Department of English and Comparative Literary Studies at Saurashtra University, Rajkot, India. His research interests include cultural studies, literary theory, and poetry.

E-mail: smukherjee@sauuni.ac.in

https://orcid.org/0000-0001-9866-9308 


\section{Politics of Assimilation and Cultural Identity}

Assimilation is sometimes viewed as an answer to the discontents of diaspora, and it simultaneously affects the way immigrants look back towards their native culture. Robert Park and Ernest Burgess (1993) define assimilation as a "process of interpenetration and fusion in which persons and groups acquire the memories, sentiments, and attitudes of other persons or groups, and by sharing their experience and history, are incorporated with them in a common cultural life". Park and Burgess' definition of assimilation does not differ markedly from Barkan's six stage model, in which total assimilation is required (1995, p.65). However, postcolonial diaspora critics advocate the multiplicity of identity construction and think of hybridity as a subversive strategy (Bhabha 1993; Trodd 2007; Guignery 2011; Nederveen Pieterse 2001; Papastergiadis 2007). Georgiou (2010), for instance, argues that the extended cultural boundaries that diaspora possess can be enabling for the construction of new and multiple domestic and collective homes. In her view, home is always ambiguous and incomplete; it is never as fixed and permanent (Georgiou, 2010). Similarly, Kołodziejczyk (2018) posits that the more we focus on identity issues, the more we limit migrant experience to the struggle for recognition in the process of settling down. If reduced to this level, the diasporic subjectivity might remain within the confines of 'fitting in' and the issues of loss and gain in the cultural process.

In diaspora studies today, there is a recognized crisis with the 'hyphen'. In his deliberations about diaspora, Vijay Mishra (2007) refers to them as people who would want to explore the meaning of the hyphen, but perhaps not press the hyphen too far for fear that this would lead to massive communal schizophrenia. Pressing either side of the hyphen results ultimately in imbalance and the diasporic subject bears the consequences. This issue is reflected in Mira Jacob's novel particularly in her juxtaposition of two immigrant generations. The Sleepwalker's Guide to Dancing (2013) is a diasporic novel that narrates the story of an Indian American family and their loss of a loved son and other family members in tragic circumstances. Though it features several joyful moments, the novel can be read as an elegy because of the tragic events that overshadow the narrative. Jacob's characters of first-generation immigrants struggle with whether to maintain a particular identity or transform it further. Remaining hyphenated, as in the case of the parents Kamala and Thomas in the novel who immigrated to the United States in the $60 \mathrm{~s}$, creates identity crisis. More importantly, revisiting the past and taking 
responsibility for certain familial decisions determine their engagement with the American culture and society. Their choice of whether to adopt either poles of the hyphen complicates their diasporic experience, very often triggering memories and instituting moments of guilt and remorse.

Apart from personal experience and the route of migrancy taken, other factors determine the type of identity that diasporas form, whether hybrid or hyphenated. The notion of 'imaginary homeland' persists, and it imbalances the position of the designated hyphen. It very often re-defines the relationship of the diasporic subject with the general society. Besides, border crossing in its totality entails mapping and imagining the world, resulting commonly in a particularly frozen view of their homeland. In any case, home, both in its real shape as a place as well as in its symbolic imaginary form, provides the initial and emotional parameters for identity (Georgiou, 2010). The ethnic tag also provides a sense of belonging, punctuating identity and multiplying affiliations. On the other hand, the acceptance and assimilation of racially mixed individuals have always encountered great ambivalence and resistance in American society (Barkan, 1995). The politics of assimilation of the receiving culture determines to a great extent the type of identity diasporas construct. Though there have been attempts to re-write the nation as an entity not associated with a pre-given people (Antonsich, 2009), essentialist identities resurge, demarcating who intrudes and who has the right to be included. De-ethnicizing and writing the nation in civic terms is a bold suggestion, yet it seems inapplicable. Ethnicity and skin colour remain among the defining markers of identity in the United States and elsewhere.

Meanwhile, Mira Jacob in her novels projects the idea that immigrants of second and third generations should be given the opportunity to choose the path that is best for them. The American model of assimilation advocated by Barkan (1995), Park and Burgess (1993) fails to address ethnic difference and the visible identificational and cultural markers of diasporas. For Barkan (1995), assimilated individuals must have lost most of their personal knowledge of their ethnic roots, or those roots had become diffused, merged with what has been absorbed from their new principal societal context. If Mira Jacob's characters are analysed according to this type of assimilation, the result is rather a conflating unconventional identification where both the receiving and sending cultures interact. Assimilation of contemporary diaspora is hybridized, involving multi-steps that 
eventually result in acculturation, adaptation, and integration. Jacob's second-generation diaspora really aspire to assimilation but not as Barkan envisions. Though hybrid in cultural identification, Amina and Akhil, Thomas's children, still show considerable association with their roots. The food that Kamala cooks for them at home, the Indian family friends, and the imaginary homeland that they cherish still constitute their Indian American identity. The assimilation that Amina, Akhil, and their friend Dimple envision is bi-directional requiring willingness of the dominant society to accept them without prior conditions. The two-way process of this type of assimilation does not necessarily mean that it is an equal cultural exchange, but it clearly indicates a cultural hybridization in which both the dominant and the diasporic societies affect and influence each other. Hence, the process of integration and Americanization that Amina and Akhil undergo remains inadequate in constituting a sense of self, and they are not in any case able to shed their ancestral heritage.

The novel provides ample cultural encounters where first-generation immigrants are usually depicted as hesitant in engaging in cultural interactions with the dominant society. This sort of resistance can be attributed to the traces of cultural heritage and punctuation of diasporic identity. For instance, Thomas and Kamala, as first-generation immigrants, remain in constant struggle with these variables. They never act as Americans and they sometimes mock themselves for faking being American. Kamala, in particular, does not exert any effort to assimilate or even explore American culture. Hence, her diasporization process is not complete and her loyalty remains to her roots. Similarly, Thomas as a brain surgeon is profoundly respected at his work not for absorbing American cultural values but for his dedication and professionalism in his medical practice. His profession and elite medical profile provide him with a badge to transcend cultural difference which his wife experiences more clearly in her day-to-day life. Though immigrants worldwide are encouraged to adjust and accommodate in order to acquire citizenship, Thomas represents the segment of Indian American diaspora of the sixties categorized often as 'highly qualified professionals'. This category of Indian diaspora obtains citizenship easily not based on assimilation and absorption of American cultural values but because of the demand for their expertise. Their knowledge and services are required more than their cultural integration as in Thomas's case. 
One of the central themes in the novel is the complexities for first-generation immigrants and the conflict between the American way of life and Indian tradition. The cultural transition through first generation to second generation diasporas is also very significant in Jacob's novel. Kamala and Thomas, being first generation immigrants, carry their cultural baggage with them and they try to transmit it to their offspring, Amina and Akhil. They expect their children to live by the value system of their Indian culture. Consequently, they force on them certain cultural markers through food, dress, customs, rituals, languages, beliefs, etc. Nevertheless, Akhil and Amina are more exposed to American culture outside their home, and they are eventually sandwiched between two cultural poles. Their cultural negotiations with both sides transform them and they not only absorb from both sides but exist in-between. In connection to this position, Barkan (1995) emphasizes that the federal government in the United States has very early given concrete recognition to the nation's ethnic pluralism. This ethnic pluralism enables both Amina and Akhil to explore both the American culture that they inhabit and the Indian culture that they inherit. Initially, Akhil reflects a negative attitude towards his identity and his 'self'. In a state of dissonance, he suffers from personal conflict with heritage. When Dimple, his cousin and Amina's friend, decides to go to Homecoming dance wearing a sari, Akhil does not approve of it at all. He protests that "Everyone would know that you are Indian, and the next thing you know, you will be asked to make 'samosas' for the whole school" (2013, p. 139). By this response, he attempts to discourage and prevent Dimple from pronouncing her cultural identity.

As a bildungsroman, the novel traces the emotional as well as the intellectual maturation of Akhil and Amina. The continual cultural explorations enable Akhil to understand his in-between position better. He no longer complains about his cultural heritage but embraces who he is and asserts that "I am not trying to be white" (2013, p. 136). All this shows that he has experienced identity crisis. More importantly, it also demonstrates that even the second-generation immigrant spends the whole day outside not to present himself as he is but to pretend to be American. This position is clearly reflected in Barkan's article about assimilation where he remarks that American society, despite its diversity, is not yet ready to be multi-coloured to the core $(2013$, p. 68). Even though cultural variation demands honest respect, colour remains a boundary that assimilation models are unable to blur. Although "one of the rights in America is the right to be different" (Gordon, 1973), the dominant society in the United States imposes its own 
criteria for acceptance and inclusion. This situation offers diasporas an in-between space in which nothing is definite or articulated.

Despite its recent history, Indian diaspora in the United States has gained a recognized visibility and strong presence in different sectors of science and technology. However, the success of any diaspora is usually attributed to its ability to assimilate and integrate into mainstream culture. First generation immigrants as depicted in Mira Jacob's novel usually struggle in their attempt to assimilate into the new culture in order to gain acceptance, and they even at certain occurrences reject associating themselves with the dominant culture. Homeland remains a haunting presence in their minds. For them, the myth of homecoming (return) remains active even though the journey back home is more fictive than actual. Diasporas do not seek return but they desire maintaining a connection with homeland. Practically, "not all diasporas wish to return home" (Brah, 1996, p. 7), and their nostalgic engagements are part of identity formation. In reality, home is a complicated political and cultural terrain where diaspora cannot physically return (Nititham, 2016 p. 41). The exile and the expatriate always envision a possible return, and this insulates the individual. On the other hand, the immigrant seeks transformation and re-rooting with a desire for continuity. This transformation, however, causes a split of the self and brings trauma, self-doubt, and uncertainties. Even when under threat, diaspora retreats and returns only to an imaginary homeland that serves only as "a romantic refuge" (Nititham, 2016, p. 41).

Invariably, diaspora remains in connection with homeland via different means and the finality of the diasporic journey is never realized. Jacob's novel clearly depicts the difficulty in setting the immigrant free from the past and its traces. Through much of the narrative, her first-generation immigrants demonstrate how the past cannot be suppressed easily. First generation diaspora cling to their food and clothes as the most obvious markers of identity that set them apart and highlight their difference. More importantly, what happens back home does not remain there but affects diasporas and re-defines their association with their ancestral past. On the other hand, their children, who are mostly second generation, engage in hybrid social and intercultural interactions. They are caught in-between trying to please parents and their American peers in order to meet both their respective expectations. Hence, they show greater flexibility in adapting and assimilating. 


\section{Intersections between Memory and Mourning}

Immigration itself is a stressful experience that often leads to altered physical and psychological health outcomes at the individual level. Cathy Caruth in her theorizing about trauma focuses on the complex permutations that unconscious emotions impose on traumatic reactions. She describes trauma as "not locatable in the simple violent or original event in an individual's past, but rather in the way its very unassimilated nature - the way it was precisely not known in the first instance - returns to haunt the survivor later on" (Caruth, 2016, p. 4). Based on Caruth's notion of trauma, Balaev describes the traumatic experience as a fixed and timeless photographic negative stored in an unlocatable place of the brain, interrupting consciousness and maintaining the ability to be transferred to non-traumatized individuals and groups (2008, p. 151). A close examination of these characteristics indicates that diasporic experience is traumatic. However, diaspora trauma is different from postcolonial trauma in terms of collectivity. In diaspora, trauma is personal for myriad of reasons and conditioned by the types of routes pursued in the journey of the immigrant. It is about loss and mourning; solely a lived experience of a traumatic event by an individual. What demarcates diaspora trauma from collective postcolonial trauma is the historical absence and re-remembering of collective past.

Vijay Mishra links South Asian diasporic trauma to the painful experiences that they underwent, such as the passage, plantation life, or events in the diaspora like the 'Komagata Maru' incident (2007, p. 3). Trauma in contemporary diaspora is mainly associated with memory, racializing, and troubled relationships with the general society. Mira Jacob's novel is ridden with loss and profound grief since the traumatic death of Thomas's family members, Ammachy, Sunil, and Akhil, causes several implications in the family's life in the United States. In the novel, trauma is mostly associated with Thomas and his mourning of a dying son, a dying mother, and a dying brother. In addition, Amina's mourning of a dying father and the tragic death of a brother, and her role as a witness to all the family's saga, complicates the narrative. The reader ultimately sympathizes with the family's loss.

The notion of an 'imagined' traumatic event is of interest here and it suggests selfconsciously ideological narratives of nationalist history as Alexander explains (2004, p. 
8), or primarily a sense of loss as recounted in diasporic narratives. Alexander's concept points to the completely illusory, nonempirical, non-existent quality of the original event (p. 9). These features are inherently diasporic and are closely associated with diasporas and their varied routes and experiences of migrancy. It is only through the memory that second and third generation diasporas have the sense of traumatic experience. It is a particular type of trauma originating in uprootedness, ethnic difference, memory, and cultural trauma in the form of racializing and profiling. It is not collective as in postcolonial or holocaust trauma where victimization is a central characteristic. The emphasis in diaspora trauma is on memory and personal experience rather than collective. Though arguments about trauma are based on ontological reality, for second and third generations of diaspora, it is purely imagined or primarily transferred from family associations or ethnic communities. Nonetheless, trauma either imagined or real is a phenomenon that abruptly and harmfully affects collective as well as individual identity.

Though he is not a fully developed character, Sunil from the beginning of the novel is depicted as a reckless individual, relying more on his brother's financial support. His relationship with Thomas is rather complicated and he frequently expresses his objection regarding Thomas's decision to permanently stay in the United States. Sunil's case is introduced early in the novel during Thomas's family's visit to Salem in India. Akhil and Amina realize that their uncle sleepwalks but their grandmother, Ammachy, tells them that it is usual and causes no harm. The title of the novel comes from Sunil's state of sleepwalking which is not truly a guide to dancing but a catastrophic incident resulting in setting the house on fire. This tragic incident results in multiple deaths, Ammachy, Thomas's mother, Sunil and his family.

The Sleepwalker's Guide to Dancing as a diaspora trauma novel offers close exploration of interiority, memory, psychological verisimilitude, and personal isolation. The sudden and untimely death of Thomas's extended family in India leaves him traumatized. His situation worsens and he subsequently traumatizes his small family in the United States. Thomas experiences a sense of guilt for refusing to stay along with his mother and brother back in Salem, India. Balaev (2008) refers to trauma as “a person's emotional response to an overwhelming event that disrupts previous ideas of an individual's sense of self and the standards by which one evaluates society" (p. 150). 
Memory of dead family members is not only social but deeply connected to the sense of the self. This sense of self is shattered when Thomas realizes that his mother and brother are dead in a tragic incident. In addition, the house in Salem as a place through metaphoric and material means functions as an effect of remembering. It is also through it as a site inhabited, viewed, or imagined that Thomas develops a melancholic feeling. It is "not only a physical location of experience, but also an entity that organizes memories, feelings, and meaning because it is the site where individual and cultural realities intersect" (Walter, 1988). Once the familial connection is lost, Thomas strongly feels that he has betrayed his family. His mother haunts him, and he spends nights talking to her spirits on the porch of the house. Much of his hallucination is seen to be a result of this guilt-ridden feeling. Ammachy represents an invaluable link to the 'homeland' which Thomas misses greatly after her tragic death. Once this link is broken, Thomas attempts to reconnect with his mother, but all attempts go in vain. He is disturbed and never finds compensation for his loss.

Akhil's bizarre case of oversleeping causes grave concern to the family. Thomas tries repeatedly to figure out his son's case, but the family eventually loses him. The whole family suffers a profound bereavement due to the loss of their beloved son, and it is another traumatic incident causing emotional as well as psychological harm. Akhil suffers a sleeping disorder, an unexplainable excess of sleep, and his sudden and unexpected death doubles Thomas's traumatic grief. The emotional disruption that he endures destabilizes his relationship with his family and he retreats to memory and imagination. These tragic incidents inform much of Thomas's trauma, and he subsequently remains stuck in the past living with the memories of his dead mother, brother, and son. In his prolonged and extreme grieving, Thomas revives memories of these deceased family members. More importantly, he imagines and feels the presence of his son Akhil, leading to frequent hallucinations that annoy his daughter and wife. These traumatic moments heighten Thomas's sense of mourning, and according to Mishra (2007), there is no immediate cure for such traumatic condition because the loss remains abstract (p. 3). Thomas's trauma is deeply internalized, and it causes severe emptiness in his ego itself which cannot be compensated for by his dignified position as a surgeon.

The narrative oscillates to and fro between the past and the present in an attempt to come to terms with the two worlds that the characters inhabit in both the native and 
the host countries. Initially, Thomas refuses to return and permanently live in India because he leads a happy life in the United States. But after his mother's death he begins to feel uprooted. Though he is a brain surgeon, he begins to act strangely, attesting to the mental strain that affects diasporas in his case. Ammachy's presence in India signifies traces of home for Thomas. Disobeying his mother and preferring to stay in the United States is equated with betraying homeland. After his mother's death, Thomas experiences an irreparable loss. He undergoes a psychological breakdown due to the series of tragic events that have struck the family: the death of his son, burning of his family's house in Salem in India, and the death of his brother and mother in the fire. In the opening conversation, Kamala casually informs Amina that her father spends his nights talking to invisible figures, including his dead mother:

“He's fine," Kamala said. "It's not like that. You're not listening."

"I am listening! You just told me he’s delusional, and I'm asking-"

"I DID NOT SAY HE IS DELUSIONAL. I SAID HE WAS TALKING TO HIS MOTHER."

"Who is dead," Amina said gently.

"Obvious."

"And that's not delusional?". (2013, p.8)

It seems that Thomas experiences a break with his family. He begins to talk with his dead mother and sees his dead son. Thomas is believed to go through a psychotic break; "a loss of contact with reality" (2013, p.197) in Amina's words. It is rather a loss of contact with homeland that he leaves behind in search of a better life in the United States. Losing his mother, brother, and the house where he was born and raised, Thomas is brutally traumatized especially when he finds that his family's house back in India is burned to ashes: "Even from a distance, they [Akhil and Amina] could see the grief radiating from him" (2013, p.147). The narrator's description of Thomas as "curled over the dining room table like a question mark" (2013, p.147) reveals how shocked he is. The presence of his mother in Salem in India was a contact link, a point of return in times of despair and alienation. All this leaves Thomas in chronic melancholia, struggling with memories and visualizations of beloved family members.

The inability to bear the motherly absence is textually depicted when Thomas is seen and heard talking to invisible figures, particularly Ammachy. Jacob illustrates the psychological and emotional bond between mother and son which gets redirected only when Ammachy is dead. The death of Ammachy leaves a void in Thomas as he slowly 
starts to drift away from his own family members. Thomas' aloofness not only preoccupied his wife but most importantly epitomizes the quandary of the diasporas at large. Ammachy, being the connecting factor with India, seems to sap this geographical bond with her death.

Thomas is haunted by his mother as she opposed his travel to and stay in the United States. Upon his visit to Salem, Ammachy, Thomas' mother, proclaims “traitors! Coward! Good-for-nothing!" (2013, p.13). Her words come as a response to Thomas' reluctance and objection to staying in India after completing his studies in America. These words may be the root cause behind Thomas's psychological disturbance. In addition, when Thomas decides to leave India for the United States, the last words he hears from his brother Sunil are "your own children will leave you and never come back" (p. 53). These words seem to have done the most damage to Thomas. When Akhil dies, these words recur and ring in Thomas' head as if Sunil's prophecy had come true. All these incidents lead to a sort of illness symptomatic of the condition of earlier generations of diasporas. Thomas' mental condition worsens and the imaginary visitations of his son and mother continue. Another incident at the hospital where he works takes the matter out of the family's confines. He tries to save a dead child, Derrick Hanson, at the hospital, drawing the medical staff's attention to his problem. His medical assistant at the hospital, Monica, meets Amina and embarrassedly informs her that her father acts strangely. Anyan George, Thomas' coworker, presents a medical opinion about Thomas' case, suggesting a brain tumour. He insists on taking medical examinations and seeking medical support to better understand Thomas's case. Under pressure from family and friends, Thomas decides to seek medical treatment. Nevertheless, after a period of improvement in his case, Thomas does not want to go for chemotherapy. When Amina asks him why, he explains that: "because the chemo will keep him [Akhil] from coming. I want to see my son" (p. 445). Thus, Thomas's hallucinations and visualizations of his dead mother and son continue until he dies in peace.

Refusing to continue treatment, the ghostly visitations are back and even Sunil is back. Thomas sees him and he reveals to Thomas that he wanted to be a dancer:

He [Sunil] said dancing was one of the things that made him happy. That if I had come back to India like I was supposed to, if he wouldn't have been left to take care of everything on his own, he would have been a dancer. (p. 446) 
Sunil's ghostly visitations explain the intersection of memory and grief that Thomas endures. The sense of guilt doubles Thomas' trauma and seizes him from his reality. The memory of Sunil flashes back clear and sharp, and Thomas interrogates himself in the presence of his daughter who acts as a witness: "can you imagine what all might have changed with that one silly thing? Maybe your mother would be happy. Maybe Akhil." (2013, p.446). It is a relief for him to hear his brother again and realize that it was his fault. Most importantly, it is a relief for Thomas to accept the blame for abandoning his family in Salem in India. In his revelation of ghostly visitations, Thomas in a desperate tone mutters: "it was a relief to hear him [Sunil] say that it was my fault. All these years, imagining how he must have hated me, cursed me, and now finally it's done, over, kaput. Now I move on, right" (p. 447). Jelin and Kaufman argue that the personalized memory of people cannot be erased or destroyed by decree or by force" (p. 94).

The popular trauma theory employed today depends upon the 'abreactive model' of trauma, which is used to assert the position that traumatic experience produces a "temporal gap" and a dissolution of the self (Balaev, 2008, p. 150). This model is developed by Caruth and it is now deployed in literary studies. With reference to Jacob's novel, trauma is a metaphor to describe the degree of damage done to the individual's coherent sense of self and the change of consciousness caused by the experience. Consciousness is seen as an inherent characteristic of traumatic experience. Kamala refers to it as 'choices', implying that Thomas understands the situation he is in yet remains reluctant to seek help. His choice seems to be a way to punish his guilt-ridden soul. In any case, Thomas endures a significant component of trauma in the novel, demonstrating the ways that the first-generation diasporas experience and endure various forms of trauma. The act of remembering adds another dimension to the family's narrative. The preoccupation with deceased family members ravages the family and turns their lives into a tragedy. Thomas's childhood photos of his brother and mother trigger memories of distress and enliven his mourning. 'Memory' in his case is, as Seyhan (2001) describes, both poison and antidote (p. 38). Remembering past painful incidents torments him mentally and physically; it is a source of trauma and mourning. Moreover, since the protagonist Amina's profession is photography, there is a recurring motif of the 'image' as a captured moment of time. The photos of people that she takes as part of her job, and the mural in Akhil's room all function as a catalyst to memory. This clearly 
reflects Jacob's notion of diasporic memory and she positions it as a double-edged sword. Her characters rely heavily on memory whether mourning catastrophic circumstances conditioned by migrancy or shaping their cultural identity in the United States.

Thomas' responses to traumas are usually attempts to alter the circumstances that caused them. His memory residues surface through free association with the past and remembering as an act situates him in a larger social context that serves as a source of mourning. Before his death, Thomas' case worsens, and he insists that Akhil is alive in the garden and will come to visit him. Even Kamala believes him this time and considers it Thomas' miracle because of his righteous work. This new collaboration between them signals the beginning of the end for the family's patriarch. Kamala lights up the whole house and the garden, believing that the lights will keep Akhil in the garden. She realizes that her husband wishes to go to his son more than he wants to stay with them. The excessive insomnia, loss of weight, and deteriorating health force Kamala to go along with her husband. The change in her evaluation from "evil" to "miracle" suggests that she offers a parting gift and a final agreement with her ailing husband. Realizing this collaboration, Amina yells: "My parents. It's weird. They go everywhere together now. The garden, the porch, probably the bathroom. It is like the sun set on the wrong side of the sky" (2013, p. 465).

Kamala is indifferent to what happens to her husband while he continues to drift away, consumed by his sadness and guilt. Instead of supporting him emotionally and trying to understand his case, she very often attributes it to the devil. Exasperated, she periodically associates her husband's behaviour with a sort of weakness. Kamala accuses Thomas' of being "tempted by bad spirits" (2013, p.307). She considers it as a kind of devilry blaming him for letting this happen. Kamala asserts "All they need is one crack and they will infest an entire soul" $(2013$, p.308). She here expresses and voices the male weakness in diasporas as Thomas is depicted. She seems to condemn the male weakness in this difficult moment represented by Thomas' choice to settle in the United States. She justifies:

There are choices, Amina! Choices that we make as human beings on this planet Earth. If someone decides to let the devil in, then of course they will see demons everywhere they look. This is not delusional. This is weakness. (2013, p. 8) 
In associating the psychological predicament of Thomas with the 'devil' and 'demons', Kamala confuses the readers with her evaluation. By referring to Thomas' case as 'choices' and 'weakness', she indirectly blames him for choosing this diasporic path of remembering and mourning. She is not only depicted as a cultural heroine resisting assimilation, but she also dominates the family's narrative and takes control of the house. Through Kamala, Jacob cleverly juxtaposes two perspectives on Thomas and his bizarre case. His wife deliberates on superstitious and religious beliefs, Thomas symbolizes the scientific, psychological and emotional reality of the diaspora in the United States. Jacob also intertextualizes Shakespeare's tragedy where the ghost preoccupies Hamlet and wears him down. Amina suggests that Akhil's ghost that visits her father is merely visual imagination. Hamlet is therefore an intertext in terms of the ghost tale and even Hamlet's melancholia is similar to that of Thomas's. The irony lies in the fact that Thomas, being a neurosurgeon, cures other patients. However, he fails to help himself in his descent into insanity. More importantly, Kamala, by reinstating that it is a matter of 'choice', not only reduces Thomas' traumatic experience to a personal choice but criticizes immigrating and leaving the homeland. She is from the beginning suspicious of living outside of India. She accompanies her husband to the United States but still longs for her homeland.

Although she is at the centre of the family in the United States, Kamala experiences a sort of uprootedness typical of first-generation immigrants. She is unhappy in the United States, and according to Vijay Mishra, unhappy diasporas are often also traumatized diasporas (2007, p 106). Her unspeakable trauma is reflected in her attitude towards her husband; reluctant and restrained. Through Kamala, Jacob employs 'silences' as a narrative strategy to create a 'gap' in time and feeling. In one sense, the unspeakable trauma of Thomas and Kamala in particular creates unresolved tensions that push the reader to imagine what might have been done or could have happened. In another sense, the gaps and silences are left for various contemplations given the non-conformity of the diasporic experience.

A central argument in literary trauma theory is that trauma creates a speechless fright that divides or destroys identity. This, according to Balaev (2008), suggests that identity is formed by the intergenerational transmission of trauma. Amina is also traumatized and endures considerable grief over the death of her brother and later her father. Her initial trauma is transferred via her father who, as first-generation immigrant, 
can be called a "carrier" as termed by Max Weber (2002, p. 468). He transmits the trauma process, inflicting it upon all of the members of the family to varying degrees. A professional photographer, Amina tries to understand the saga of her family. She is a watchfully observant of what happens to the family and realizes that the only way she can help her father is by understanding her family's painful past. In doing so, she must come to terms with the ghosts that haunt all the family. She, therefore, listens to her father's ghost revelations and converses with him in an attempt to alleviate his pain and grief. Amina is also a witness to the mother-son and brother-brother conflict which later overshadows Thomas' life. She closely monitors how her father diminishes as a result of the extreme grief.

Since traumatic experience is contagious, Amina's trauma is not her own but precisely an intergenerational type of trauma. In her unspeakable trauma, Amina refuses to talk to her colleagues and friends about her father's case. Moreover, she experiences a deep psychological break and has to endure the emotional pressure generated by such a dysfunctional immigrant family. She is not only traumatized by her brother's death whom she recurrently remembers and imagines wherever she goes - but also copes with the case of an ailing father and a ranting mother. In addition to observing the world through her camera lens, Amina is a witness to all the catastrophes that are inflicted on the family.

There are multiple deaths in Jacob's novel rendering it a tragic epic. There are not only the deaths of Akhil, Ammachy, and Sunil that cast a shadow over the narrative but also the deaths of other people not related to the Thomas' family. Though there are certain moments of warmth and unity, a sense of grief and loss dominates most of the narrative. Jacob's novel, according to trauma theory in literary studies, serves as a preservation of diasporic trauma; the themes of victimization and melancholia channel a sort of transferability of the diaspora traumatic experience. Since transmission of trauma is re-conceptualized to include practically all situations where trauma is involved (Visser, 2011), Jacob links her traumatized characters to a place and memory which function as a source of anguish. She does not project a sense of psychic resilience but presents an example of a weak and guilt-ridden immigrant. Thomas cannot dissociate himself from homeland and the memories of his deceased son and mother. 
It seems that Thomas and Kamala see themselves as illegitimate in claiming both American and Indian cultures. Their attachment to India is stronger, and in the United States, Kamala in particular, clings to everything that connects her to and reminds her of India. Both Thomas and Kamala remain fearful and suspicious of the new culture that they encounter upon a daily basis. The conflict of loyalties becomes apparent when Thomas loses his brother and mother in a house fire in India. However, they grant their children a chance to take the best of both Indian culture and American cultures. Thomas is deeply saddened by his son's death, and he buries himself in his work at Albuquerque hospital. He refuses to seek help, and he consequently starts hallucinating and speaking to the dead. After the burning of the house in India, memories of the dead flash back and haunt Thomas in addition to the visitations of his deceased son-Akhil. The family is haunted by the presence of Akhil, too. His belongings: - jacket and photos in particular trigger memories and cause emotional distress. His room becomes a sanctuary for his parents and the narrator indicates that "there was still the smell of him in the room" (2013, p. 357). The simple description of the family is that it is dysfunctional, coping with memory, trauma, and grief. The tragic memories of the family they leave behind in India are, for Thomas in particular, an uncomfortable presence and they loom large over the narrative.

\section{Conclusion}

The novel explores how grief defines the life of an Indian immigrant family and how they deal with it in the United States. The textual analysis indicates that total assimilation that involves erasure of ancestral cultural heritage is never achievable as long as ethnic difference is observable. The Sleepwalker's Guide to Dancing is a trauma novel, conveying a diversity of extreme emotional states. Through dramatic shifts in family's history, temporal fixtures, silences, and visceral traumatic details, Jacob delineates a painful diasporic experience mediated by loss and trauma. Moreover, by employing a nonlinear narrative strategy, she emphasizes the mental confusion and chaos that penetrated the lives of first-generation immigrants. The intensity of trauma delineated in the novel qualifies it as a diasporic trauma narrative; contagious and intergenerational. It differs from postcolonial trauma, for it merely traces the individual response to traumatic events. The multiple deaths in the novel create a sense of insecurity 
and panic. Nevertheless, what Jacob projected in her novel is rather a particular diasporic condition characteristic of first-generation immigrants.

\section{References}

Alexander, J. C. (2004). Toward a Theory of Cultural Trauma. Cultural Trauma and Collective Identity. Berkeley. https://doi.org/10.1525/california/9780520235946.003.0001

Antonsich, M. (2009). On territory, the nation-state and the crisis of the hyphen. Progress in human geography, 33(6), 789-806. https://doi.org/10.1177/0309132508104996

Balaev, M. (2008). Trends in literary trauma theory. Mosaic: A journal for the interdisciplinary study of literature, 149-166.

Barkan, E. (1995). Race, Religion, and Nationality in American Society: A Model of Ethnicity - From Contact to Assimilation. Journal of American ethnic History 14(2), 38-101.

Bhabha, H. (1993). Location of Culture. Routledge.

Brah, A. (1996). Cartographies of diaspora: Contesting identities. Psychology Press.

Caruth, C. (2016). Unclaimed experience: Trauma, narrative, and history. JHU Press.

Georgiou, M. (2010). Identity, space and the media: Thinking through diaspora. Revue européenne des migrations internationales, 26(1), 17-35. https://doi.org/10.4000/remi.5028

Gordon, M. M. (1973). Assimilation in American life: The role of race, religion, and national origins. Oxford University Press on Demand.

Guignery, V. (2011). Hybridity, Why It Still Matters. In Vanessa Guignery. Catherine Perso-Miquel, \& Francois Specq (Eds.), Hybridity: Forms and Figures in Literature and the Visual Arts (pp. 1-10). Cambridge Scholars Publishing.

Jacob, M. (2013). The Sleepwalker's Guide to Dancing. Bloomsbury.

Jelin, E., \& Kaufman, S. G. (2017). Layers of memories: twenty years after in Argentina. In Timothy, G. A., G. Dawson, M. Roper. (Eds.), Commemorating War: The Politics of Memory (pp. 89-110). Routledge. https://doi.org/10.4324/9781315080956

Kołodziejczyk, D. (2018). From Exile to Migrancy: Eastern and Central European Models of Cosmopolitical Writing. Journal of Austrian-American History, 2(2), 91-115. https://doi.org/10.5325/jaustamerhist.2.2.0091

Mishra, V. (2007). The literature of the Indian diaspora: theorizing the diasporic imaginary. Routledge. https://doi.org/10.4324/9780203932728 
Nederveen Pieterse, J. P. (2001). Hybridity, so what? The Anti-hybridity Backlash and the Riddles of Recognition. Theory, Culture \& Society 18(2), 219-245. https://doi.org/10.1177/02632760122051715

Nititham, D. S. (2016). Making home in diasporic communities: Transnational belonging amongst Filipina migrants. Routledge. https://doi.org/10.4324/9781315593333

Papastergiadis, N. (2018). The turbulence of migration: Globalization, deterritorialization and hybridity. John Wiley \& Sons.

Park, R. E., \& Burgess, E. W. (1993). Introduction to the Science of Sociology. Chicago University Press.

Seyhan, A. (2001). Writing outside the Nation. Princeton University Press. https://doi.org/10.1515/9781400823994

Trodd, Z. (2007). Hybrid Constructions: Native Autobiography and the Open Curves of Cultural Hybridity. In: Jopi Nyman and Joel Kuortti, (Eds.), Reconstructing Hybridity: Post-Colonial Studies in Transition (pp. 137-161). Rodopi. https://doi.org/10.1163/9789401203890 009

Visser, I. (2011). Trauma theory and postcolonial literary studies. Journal of Postcolonial Writing, 47(3), 270-282. https://doi.org/10.1080/17449855.2011.569378

Walter, E. V. (1988). Placeways: A theory of the human environment. UNC Press Books.

Weber, M. (2002). The Protestant ethic and the "spirit" of capitalism and other writings. Penguin.

2. Tadd Graham Fernée, PhD, New Bulgarian University, Bulgaria

\section{Handling Editor:}

Stan Bogdanov, PhD

New Bulgarian University 